\title{
TRIK STRATEGI MENJADI \\ KEPALA SEKOLAH \\ PROFESIONAL
}

\section{Udchiatul Liddinia}

Universitas Nahdlatul Ulama Sidoarjo

\section{Pengantar}

Menjadi pimpinan kepala sekolah atau pemilik sekolah atau wirausahawan pendidikan untuk manajemen pendidikan memiliki tantangan tersendiri. Ini bukan profesi yang mudah. Ini adalah pekerjaan dengan stres tinggi yang tidak dilengkapi oleh kebanyakan orang. Deskripsi pekerjaan kepala sekolah sangat luas. Mereka memiliki hampir semua hal yang berkaitan dengan siswa, guru, dan orang tua. Mereka adalah pengambil keputusan utama di gedung itu. Seorang kepala sekolah yang sukses melakukan berbagai hal secara berbeda. Seperti halnya profesi lain, ada kepala sekolah yang unggul dalam apa yang mereka lakukan dan mereka yang tidak memiliki keterampilan yang diperlukan untuk menjadi sukses. Sebagian besar kepala sekolah berada di tengah-tengah kisaran itu. Kepala sekolah terbaik memiliki pola pikir tertentu dan filosofi kepemimpinan yang memungkinkan mereka untuk berhasil. Mereka 
memanfaatkan kombinasi strategi yang membuat diri mereka dan orang lain di sekitar mereka lebih baik sehingga memungkinkan mereka untuk sukses. Berikut adalah beberapa tips untuk memulai dan mengelola sekolah bagi anda.

\section{Pelajari Nama Siswa}

Mungkin sulit ketika Anda melihat ratusan siswa mempelajari nama mereka. Tetapi mengetahui nama siswa adalah penting untuk manajemen kelas yang efektif. Pertimbangkan menggambar sketsa, mengambil foto, atau bahkan meminta siswa merekam video pendek. Letakkan praktik di tempat yang memungkinkan Anda mempelajari nama siswa sambil memastikan Anda mengatakannya dengan benar. Buatlah tujuan untuk mengucapkan nama setiap siswa setidaknya satu kali di setiap kelas. Ini membantu Anda mengingat nama mereka dan membantu mereka merasa terlihat. Alih-alih menggunakan daftar kelas yang disediakan oleh panduan, saya membuat formulir saya sendiri yang memungkinkan ruang untuk catatan dan sketsa (Kane, 2018). Siswa perlu memahami apa yang diketahui dan apa yang diminta untuk memiliki kemampuan menjawab (Suci et al., 2018).

\section{Jadi Baik}

Ingat tujuan utama Anda adalah meninggalkan sekolah di tempat yang lebih baik daripada yang Anda 
temukan. Jadilah strategis, bekerjalah dengan dewan sekolah Anda untuk membuat rencana strategis baru yang inovatif untuk mendorong sekolah agar berhasil di masa depan (Driscoll, 2018).

\section{Makan dengan Baik}

Jika Anda ingin mengoptimalkan kinerja mental dan fisik Anda, Anda akan memprioritaskan makan dengan baik (Bauer, 2019). Guru merupakan seorang pendidik dan pengajar sekaligus sebagai pembentuk kepribadian siswa yang unggul, berwawasan dan baik (Maula et al., 2018).

\section{Nilai Masa Lalu}

Luangkan waktu untuk mempelajari semua yang terjadi di sekolah sebelum Anda tiba. Pelajari tentang tradisi, inisiatif, keberhasilan dan kegagalan sekolah (Driscoll, 2018).

\section{Berolahraga}

Anda akan mulai atau melanjutkan berolahraga. Ditambah latihan adalah penghilang stres yang hebat dan beberapa ide terbaik saya telah dihasilkan di luar kantor sambil mengangkat atau berlari (Bauer, 2019). Pemimpin sekolah dan wirausaha pendidikan seharusnya senantiasa menikmati proses karena tidak ada hal yang besar yang tidak dilakukan dari hal yang kecil. Semua butuh 
proses, karena kesuksesan tidak datang secara langsung tanpa berproses (Maula et al., 2017).

\section{Ubah Kebijakan Perekrutan Anda}

Rahasia ini dapat membuat perbedaan: Pekerjakan staf yang cakap! Mereka jauh lebih mudah dikelola dan ironisnya, mereka membutuhkan lebih sedikit manajemen. Tetapkan standar sejak dini untuk jenis guru dan staf yang ingin Anda ajak bekerja sama. Jika Anda melakukannya dengan benar, mereka haruslah orang-orang yang dapat Anda percayai untuk membuat keputusan tanpa input konstan Anda. Ini adalah salah satu cara paling pasti untuk menjadikan pekerjaan Anda sebagai administrator lebih dari mimpi buruk (Okoli, 2017).

\section{Kepala Sekolah Efektif}

Kepala Sekolah yang efektif menekankan apa yang kita lakukan agar siswa kita berhasil, fokus pada orang, bukan pada program dan memberdayakan orang lain (fakultas, siswa, orang tua) (Harris, 2019). Pendidikan Indonesia membutuhkan peningkatan akses, mutu dan relevansi pendidikan untuk memberi manfaat membangun bagi pendidikan dan rakyat Indonesia (Irawan et al., 2018). 


\section{Mendelegasikan Tugas}

(Okoli, 2017) menjelaskan apa yang tidak boleh dilakukan sama pentingnya dengan memutuskan apa yang harus dilakukan. Menurut File Kepala educationworld, delegasi adalah salah satu solusi kunci untuk manajemen sekolah. Sebagai aturan praktis, setiap pemimpin harus tahu cara mendelegasikan. Ini berarti seorang administrator sekolah harus tahu bahwa tidak semua tugas adalah tugasnya sendiri. Dibutuhkan banyak latihan untuk menyelesaikan tugas mana yang didelegasikan dan kepada siapa. Sebagian besar administrator sudah mempraktekkan ini dalam beberapa bentuk tetapi ada 2 kesalahan umum bahkan yang terbaik dari kita membuat saat mendelegasikan:

- Anda tidak mendorong tanggung jawab kelompok: Mungkin ide yang bagus untuk didelegasikan saja tetapi dapat dengan mudah menjadi bumerang jika semua orang mulai berpikir bahwa pekerjaan orang lain bukanlah masalah mereka. Dengan mendorong tanggung jawab kelompok, setiap anggota tim mungkin bertanggung jawab untuk melakssiswaan tugas, tetapi seluruh tim bertanggung jawab.

- Anda tidak bermain sesuai dengan kekuatan: Kenali tim Anda. Mustahil untuk didelegasikan secara efisien ketika Anda tidak sepenuhnya memahami kekuatan dan kelemahan anggota staf. Jauh lebih mudah ketika Anda menempatkan 
orang-orang yang bertanggung jawab atas areaarea yang merupakan pakaian kuat mereka.

\section{Memiliki Visi untuk Sekolah Anda}

Cara memimpin sekolah adalah senantiasa musyawarah serta sharing bersama para guru atau dengan siapapun dan tetap mendekat pada Allah SWT (Yuniarti et al., 2017).

Anda harus percaya pada visi Anda jika Anda ingin menginspirasi staf Anda untuk bergabung dengan tujuan yang sama (Drewitt, 2017). Kesabaran dan komunikasi yang baik dengan masyarakat sekitar adalah kunci untuk dapat mengatasi masalah dan bisa bangkit dari keterpurukan manajemen pendidikan. Prinsip utama dan kepemimpinan wirausaha pendidikan adalah disiplin, kreatif, cerdas dan ulet (Qori'ah et al., 2017).

\section{Belajar Mendelegasikan}

Pemimpin yang baik memahami tanggung jawab mereka; pemimpin hebat memahami tanggung jawab mereka dan bagaimana mendelegasikannya. Jika Anda lebih berkepribadian tipe A, Anda mungkin kesulitan mendelegasikan tugas pekerjaan Anda. Anda mungkin ingin melakukan semuanya sendiri untuk memastikan itu dilakukan untuk kekhususan Anda. Adakan pertemuan dengan tim Anda setiap minggu atau setiap dua minggu untuk memastikan Anda semua 
pada halaman yang sama dengan siapa yang melakukan tugas apa. Hadiahi tim Anda karena membantu Anda dengan cara-cara kecil. Membawa kopi dan donat atau hanya mengucapkan "terima kasih" sederhana akan menunjukkan bahwa Anda menghargai bantuan mereka (Kerns, 2016).

\section{Merumuskan Visi}

Setiap orang di kepemimpinan sekolah ingin meningkatkan kinerja akademik peserta didik, tetapi dibutuhkan pemimpin yang kuat untuk merumuskan visi yang dapat dicapai untuk mencapai itu. "Membentuk visi keberhasilan akademik untuk semua siswa, yang didasarkan pada standar yang tinggi," adalah yang pertama dari lima praktik yang tercantum dalam "Kepala Sekolah Efektif: Lima Praktik Penting yang Membentuk Kepemimpinan Instruksional." Selain itu, visi tersebut harus disertai oleh daftar langkah-langkah yang perlu ditindaklanjuti yang diperlukan untuk mencapai visi. Langkah-langkahnya mungkin termasuk pertemuan dengan siswa dan orang tua mereka untuk menunjuk ke arah kursus yang tepat, menggunakan lebih banyak tutor, dan melatih guru dalam metode pengajaran baru (Watanabe-Crockett, 2018). 


\section{Terima bahwa Anda tidak sempurna}

Dan juga sadari bahwa konsep ini berlaku juga untuk orang lain (Drewitt, 2017). Tips kelola sekolah adalah senantiasa belajar dan bekerja keras. Bersabarlah dengan masalah, sesungguhnya didalam kesulitan ada kemudahan (Sholichah et al., 2017).

\section{Tangani Dokumen Hanya Sekali}

Jadikan prioritas untuk menangani kertas hanya satu kali. Selesaikan tugas dengan segera, ajukan, atau delegasikan tugas tersebut ke orang lain di tim Anda. Jangan biarkan kertas menumpuk berpikir Anda akan berurusan dengan mereka nanti. Hanya lebih banyak yang akan datang dan jumlah dokumen bisa menjadi luar biasa! Sedangkan untuk email, atur waktu tertentu sepanjang hari untuk membaca dan menghadapinya. Datang beberapa menit lebih awal untuk membaca email memungkinkan Anda untuk memulai hari dengan barang-barang yang sudah ada di piring Anda. Tangani email saat Anda mengerjakan dokumen: jawaban, file, atau delegasikan. Jangan menunda berurusan dengan email ke waktu lain hanya akan ada lebih banyak (Communicator, 2017).

\section{Jangan Menjadi Gila Kerja}

Manajemen sekolah dilakukan dengan menerapkan standar kualitas dalam rekrutmen 
pengajar yaitu kedekatannya dengan amaliyah (Munjidah, Zannah, Purnomo, \& Rosyidah, 2017).

Jaga dirimu dan gurumu. Dorong staf Anda untuk pulang ke kehidupan yang sehat dan seimbang (Drewitt, 2017).

\section{Menyiapkan Ruang Kerja yang Terorganisir dengan Baik}

(Springer, 2019) Tentukan ruang yang dekat dengan bantuan mudah dan check-in, tetapi tidak begitu dekat sehingga Anda menghambat kebebasan. Kamar tidur, dan terutama tempat tidur, kurang diinginkan untuk ditempati ruang kerja ini daripada area umum seperti dapur atau ruang makan. Jadikan ruang bebas dari kekacauan, dan pimpin siswa Anda dalam membangun kebiasaan membersihkan setelah selesai.

- Berikan pencahayaan yang cukup.

- Pilih ruang yang tenang dan bebas dari gangguan berlebihan.

- Menyediakan penyimpanan yang dapat diakses untuk bahan-bahan seperti pensil, kertas, spidol, gunting, selotip, dll.

- Gunakan timer untuk menetapkan waktu istirahat, dan menilai kemajuan selama waktu istirahat.

- Berikan map atau kotak file akordeon dengan folder. Ini dapat digunakan untuk menyimpan 
panduan belajar dan bahan referensi, dan makalah penting yang pulang dari sekolah.

\section{Religius}

Setiap manusia hamba Tuhan yang memiliki ilmu selayaknya harus mengamalkan ilmu tersebut (Asitah et al., 2017). Pendidikan adalah kunci untuk membuka pintu emas kesuksesan. Wirausaha pendidikan dengan motivasi bisnis dengan Allah Ta'ala sebagai bentuk kenyamanan untuk ibadah. Tips mengelola institusi pendidikan adalah niat mendidik dan berjuang karena Allah ta'ala. Niscaya rintangan sebesar apapun akan terasa ringan dihadapan kita. Melihat anak mengenal Allah Ta'ala dan sukses akhlak dan pengetahuannya merupakan kebahagiaan pendidik (Yuniarti, Kautsari, Sholichah, Purnomo, \& Rosyidah, 2017). Prinsip pendidikan adalah sosial. Sebagai seorang guru, kita harus memiliki kepedulian sosial (Asitah et al., 2017). Guru harus bisa membangun generasi muda untuk masa depan. Hiduplah untuk mengamalkan ilmu (Sholichah, Istiqomah, Rosyidah, $\&$ Purnomo, 2017). Hubungan pendidikan antara guru dan murid itu seperti aliran listrik dengan lampu. Bagaimana lampu itu bisa menyala kalau aliran listriknya juga mati ?. Bagaimana murid itu bisa berprestasi sedangkan guru sendiri tidak pernah berprestasi dan mendoakan (Fidiana, Istiana, Rosyidah, \& Purnomo, 2017). 


\section{Berkolaborasi pada Prioritas}

Sejauh teori berjalan sebagian besar sekolah ingin guru mereka untuk bergabung satu sama lain untuk membuat pelajaran, berbagi berbagai sumber daya dan ide, dan mengatasi kebutuhan belajar individu siswa. Namun, kebenarannya adalah bahwa dalam kebanyakan kasus mereka tidak benar-benar memiliki waktu untuk melakukannya. Dalam kebanyakan kasus, istirahat maksimum yang guru miliki di antara kelas adalah 20 menit dan kadangkadang bisa turun menjadi 5 menit juga. Tidak banyak waktu untuk berdiskusi dengan kolega Anda. Di sinilah Anda administrator harus berpikir dan berpikir keras (Fedena, 2018).

\section{Makna Pendidikan}

Hasil penelitian menunjukkan bahwa penerapan pembelajaran dapat meningkatkan prestasi siswa; dan tes menunjukkan bahwa prestasi belajar siswa kelas belajar lebih baik daripada siswa kelas konvensional (Iskandar, Rizal, Kurniasih, Sutiksno, \& Purnomo, 2018). Pendidikan itu sebuah perhiasan dalam kemakmuran dan tempat bernaung dalam kesengsaraan (Maula, Mufidah, Rosyidah, \& Purnomo, 2017). Guru merupakan seorang yag memilki tugas mulia sebagai pendidik dan pengajar sekaligus sebagai pembentuk kepribadian siswa (Maula et al., 2018). Cari ilmu yang bermanfaat dan 
patuhi aturan-aturan yang ada. Bijaksana dan pantang menyerah dalam belajar adalah kunci kesuksesan. Pendidikan adalah pelajaran yang harus kita pelajari setiap hari baik dari buku, lingkungan, teman, maupun keluarga agar kita tidak tertinggal (Qori'ah, Sholichah, Purnomo, \& Rosyidah, 2017).

\section{Kalender Tahunan Kepala Sekolah Primer}

Kalender ini akan membantu Anda menyimpan ikhtisar bulan ke bulan tentang apa yang ada di depan sehingga Anda dapat membawa koherensi ke dalam perencanaan Anda (Educational Leaders, 2019).

\section{Belajar No.1}

Pemimpin sekolah sebisanya tegas, toleran terhadap bawahannya dan mengayomi. Pendidikan adalah catatan masa lalu dan pengajaran masa kini untuk masa depan bangsa.

Pendidikan adalah menyampaikan ilmu dan mentransformasi orang lain menjadi lebih baik (Fidiana et al., 2017). Pahami bahwa intinya di sekolah mana pun adalah belajar dan alasan \# 1 Anda ada di sana adalah untuk para siswa. Buat keputusan berdasarkan apa yang terbaik untuk siswa dan pembelajaran siswa setiap saat (Driscoll, 2018). 


\section{Jiwa Wirausaha}

Edupreneur atau educational entrepreneur berasal dari dua kata yaitu education bermakna pendidikan dan entrepreneur bermakna pengusaha atau wirausahawan. Ada juga yang menyamakan istilah edupreneur dengan istilah teacherpreneur (Purnomo, 2017). Menjaga hubungan baik dengan wali siswa melalui melaksanakan janji dan pelayanan yang baik adalah bagian dari promosi wirausaha (Asitah, Usmawati, Rosyidah, \& Purnomo, 2017). Toleransi, bekerja sama, bertanggungjawab, dan amanah adalah prinsip wirausaha pendidikan (Nahdiyah, Amrina, Purnomo, \& Rosyidah, 2017).

\section{Pertahankan Aksesibilitas}

Sebagai kepala sekolah, mudah untuk begitu sibuk sehingga Anda menutup pintu kantor untuk mencoba dan menyelesaikan beberapa hal. Ini sangat dapat diterima selama tidak dilakukan secara teratur. Kepala sekolah harus dapat diakses oleh semua pemangku kepentingan termasuk guru, anggota staf, orang tua, dan terutama siswa. Setiap kepala sekolah harus memiliki kebijakan pintu terbuka. Kepala sekolah yang sukses memahami bahwa membangun dan memelihara hubungan yang sehat dengan semua orang yang bekerja dengan Anda adalah komponen kunci untuk memiliki sekolah yang luar biasa. Menjadi permintaan tinggi datang dengan pekerjaan. Semua 
orang akan datang kepada Anda ketika mereka membutuhkan sesuatu atau ketika ada masalah. Selalu sediakan diri Anda, jadilah pendengar yang baik, dan yang paling penting tindak lanjuti sebuah solusi (Meador, 2019). 


\section{References}

Asitah, N., Usmawati, D. Z., Rosyidah, E., \& Purnomo, A. (2017). MI Hasyim Asy'ari Ilmu Harus Terus Mengarus. In Wirausaha Pendidikan Indonesia (Jilid 2). Sidoarjo: UNUSIDA Press.

Bauer, D. (2019). 200 Tips for Effective School Leaders. Retrieved June 11, 2019, from https://www.betterleadersbetterschools.com/200-tipseffective-school-leaders/

Communicator. (2017). 4 Time Management Tips for Principals. National Association of Elementary School Principals, 40. Retrieved from https://www.naesp.org/communicator-june-2017/4time-management-tips-principals

Covey, S. (1996). First things first. New York: Simon and Schuster.

Drewitt, P. (2017). 25 tips for School Principals. Retrieved June 10, 2019, from https://www.linkedin.com/pulse/25-tips-schoolprincipals-paul-drewitt

Driscoll, M. (2018). 16 Success Tips for New 21st Century Principals. Retrieved June 23, 2019, from https://thinkstrategicforschools.com/16-success-tipsnew-21st-century-principals/

Edsys. (2016). 10 Awesome Tips to Manage School Discipline Issues. Retrieved June 27, 2019, from https://www.edsys.in/10-awesome-tips-to-manageschool-discipline-issues/

Educational Leaders. (2019). Guides for managing your school. Retrieved June 28, 2019, from http://www.educationalleaders.govt.nz/Managingyour-school/Guides-for-managing-your-school 
Fedena. (2018). Quality tips for better school management. Retrieved June 24, 2019, from https://fedena.com/blog/2018/11/quality-tips-forbetter-school-management.html

Fidiana, W., Istiana, Z., Rosyidah, E., \& Purnomo, A. (2017). MINU Waru 2 Insan Berkilau Cahaya Manfaat. In Wirausaha Pendidikan Indonesia (Jilid 4). Sidoarjo: UNUSIDA Press.

Harris, S. (2019). 10 Survival Tips for New, Struggling School Principals. Retrieved June 21, 2019, from https://www.teachhub.com/10-survival-tips-forschool-principals

Irawan, D. E., Purnomo, A., Sutiksno, D. U., Abraham, J., Alamsyah, A., Saputra, D. H., ... Rosyidah, E. (2018). Kajian Pendidikan Tinggi IDRI untuk DPR RI dan Ristek Dikti 2018. Bandung: ITB Press.

Iskandar, A., Rizal, M., Kurniasih, N., Sutiksno, D. U., \& Purnomo, A. (2018). The Effects of Multimedia Learning on Students Achievement in Terms of Cognitive Test Results. Journal of Physics: Conference Series, 1114(1), 012019. https://doi.org/10.1088/1742-6596/1114/1/012019

Kane, A. (2018). 5 Essential Tips for Managing High School Students. Retrieved June 23, 2019, from https://theartofeducation.edu/2018/07/02/5-essentialtips-for-managing-high-school-students/

Kerns, K. (2016). 5 Time Management Tips for School Administrators. Retrieved June 26, 2019, from http://help.thesubservice.com/blog/5-timemanagement-tips-for-school-administrators Maula, I., Asitah, N., Munjidah, A., Nahdiyah, K., Yuniarti, D., Sholichah, S. A., ... Qori'ah, S. (2018). Kontribusi Kreativitas Guru SD dalam Induksi Pembelajaran. https://doi.org/http://doi.org/10.17605/OSF.IO/BS79 
Maula, I., Mufidah, F. I., Rosyidah, E., \& Purnomo, A. (2017). SD Antawirya Islamic Javanese School Mother is Culture. In Wirausaha Pendidikan Indonesia (Jilid 1). Sidoarjo: UNUSIDA Press. Meador, D. (2019). 10 Things a Successful School Principal Does Differently. Retrieved June 25, 2019, from https://www.thoughtco.com/things-asuccessful-school-principal-does-differently-3194532

Munjidah, A., Zannah, I. P. N., Purnomo, A., \& Rosyidah, E. (2017). MI Thoriqussalam Berpegang Kepada Rosul. In Wirausaha Pendidikan Indonesia (Jilid 4). Sidoarjo: UNUSIDA Press.

Murray, J. (2018). Time Management Tips for School Leaders - Part I. Retrieved June 25, 2019, from https://www.ccu.edu/blogs/cags/2018/01/timemanagement-tips-for-school-leaders-part-i/

Nahdiyah, K., Amrina, S., Purnomo, A., \& Rosyidah, E. (2017). SD Taman Pendidikan Islam Porong Iman Kuat Bekal di Akhirat. In Wirausaha Pendidikan Indonesia (Jilid 2). Sidoarjo: UNUSIDA Press.

Okoli, A. (2017). 3 Little Changes that Would Make a Big Difference to your School Management. Retrieved June 29, 2019, from https://safsms.com/blog/3changes-to-improve-school-management/

Peel District School Board. (2019). Becoming an Effective Youth Leader. Retrieved June 20, 2019, from http://www.peelschools.org/students/studentactivityc ouncil/tipsforbeingeffectiveschoolleader/Pages/defau lt.aspx

Purnomo, A. (2017). Pengertian Edupreneur. https://doi.org/10.31227/osf.io/8fnu6 
Qori'ah, S., Sholichah, S. A., Purnomo, A., \& Rosyidah, E. (2017). Progresif Bumi Sholawat dengan Kebenaran Semua Pasti Ada Jalan. In Wirausaha Pendidikan Indonesia (Jilid 3). Sidoarjo: UNUSIDA Press.

Sholichah, S. A., Istiqomah, A., Rosyidah, E., \& Purnomo, A. (2017). MI Darun Najah Berfikir Berkarya Berdzikir. In Wirausaha Pendidikan Indonesia (Jilid 3). Sidoarjo: UNUSIDA Press.

Springer. (2019). Tips for Managing Organization.

Retrieved June 29, 2019, from https://www.springerld.org/springer-experience/center/parentprograms/tips-organization

Suci, S. H. A., Rosyidah, E., Asitah, N., Aini, N., Murni, A. W., Anam, F., ... Kuraesin, A. D. (2018).

Learning from Picture and Picture Action Research : Enhancement of Counting Ability on Division of Numbers for Primary School Students. Journal of Physics: Conference Series, 1114(1), 012044. https://doi.org/10.1088/1742-6596/1114/1/012044 Watanabe-Crockett, L. (2018). The 10 School Leadership Best Practices That Make a Difference. Retrieved June 20, 2019, from https://www.wabisabilearning.com/blog/10-schoolleadership-best-practices

Yuniarti, D., Kautsari, M. F., Sholichah, F., Purnomo, A., \& Rosyidah, E. (2017). SMP SMA Al-Amin Ponpes Bahrul Hidayah Serahkan pada Allah Ta'ala. In Wirausaha Pendidikan Indonesia (Jilid 1). Sidoarjo: UNUSIDA Press. 